\title{
Buyers of Lemons: Addressing Buyers' Needs in the Market for Lemons with Blockchain Technology
}

\author{
Liudmila Zavolokina \\ University of Zurich \\ zavolokina@ifi.uzh.ch
}

\author{
Gianluca Miscione \\ University College Dublin \\ gianluca.miscione@ucd.ie
}

\author{
Gerhard Schwabe \\ University of Zurich \\ schwabe@ifi.uzh.ch
}

\begin{abstract}
The automotive market is in the top three markets with the least trust from consumers. In particular, in the second-hand car market, consumers suffer from such problems as the car being in worse condition than initially indicated, accident damage that is not disclosed, fraud, etc.

Akerlof, described the market for used cars as an example of the problem of information asymmetries and resulting quality uncertainty. In order to cope with quality uncertainties, used car buyers actively engage themselves in information seeking. Blockchain technology promises to automatize the tracking of cars through their lifecycles and provide reliable information at any point in time it is needed. In our study, we investigate the problems car buyers face during information seeking and propose requirements for the design of a blockchain-based system to address these.
\end{abstract}

\section{Introduction}

The used car market is characterized by uncertainty and lack of trust. A consumer study, conducted in Germany in 2017, found that the automotive market is the least trusted [1], while at the same time being among the largest [2]. In used car markets in particular, consumers experience such problems as fraud, the dishonest behavior of sellers and having no way to verify information about used vehicles [3]. In Europe alone, mileage fraud in used cars costs between $€ 5.6$ and $€ 9.6$ billion per year [4].

Today there are several ways to check the accuracy of parameters such as mileage, being accident-free, if services have been done appropriately, etc., but none of them are perceived as particularly reliable, and they need to be conducted by experts. Blockchain technology (or a distributed ledger) promises to automatize the tracking of cars through their lifecycles and provide reliable information at any point in time it is needed [5]. Due to such characteristics as distributed operation, immutability of records and cryptography, there is a possibility to address the problem of fraud and lack of transparency in the used car market by creating a blockchain-based vehicle history report. The problem with second-hand cars is a long-standing one and was used as an illustration in Nobel laurate G.A. Akerlof's theorization about quality uncertainty, information asymmetry and their outcomes in his "Market for 'Lemons': Quality Uncertainty and the Market Mechanism" [6]. Akerlof's paper refers to the used car market as an example of the problem of asymmetry of information, quality uncertainty and, as its consequence, the decreasing value generated in those markets because quality goods are undervalued and thus sold elsewhere. Indeed, if the buyer of a used car does not have information about the car they intend to buy to the same extent as the seller does (normally as a consequence of several not-always-traceable variables, such as the owner's driving style, quality and frequency of maintenance, and accident history), then "bad" cars (called "lemons"-defective cars) supersede good ones to their complete extinction in the used car market.

The problem of information asymmetry and product quality uncertainty manifests itself in two ways: (1) at the micro level of buyers and sellers coping with uncertainty. This can be studied by checking what practical strategies to reduce information asymmetries are put in place, for instance: calling a friend, checking reviews and reading specialized magazines; and (2) the broader market effect of bad products driving out good products. In order to deal with the effects of quality uncertainty, institutions develop measures to counteract the effects of quality uncertainty such as warranties, certifications, brand names and chains of organizations.

The present study takes the micro-level view summarized in point (1): rather than on the whole market, we focus on individuals' information seeking behaviors. More precisely, we focus on how secondhand car buyers try to reduce the asymmetry of information they are exposed to. Then, we make proposals about how those insights can be used to 
formulate requirements for a blockchain-based system to increase trust between involved parties. In our study, we state the following research questions:

RQ1: What problems do car buyers face in the used car market during the information seeking phase?

RQ2: What requirements should be placed for the design of a blockchain-based system to address these problems?

Regarding information seeking behaviors to reduce information asymmetry, this paper takes an exploratory approach. It presents and discusses the results of interviews and a survey with second-hand car buyers on the problems they face during searches for necessary information. Regarding design implications, we discuss what requirements should be in place for a blockchain-based system that aims to mitigate information asymmetry between buyers and sellers in a second-hand car market due to its characteristics. Against this broad background, this paper focuses on the used car market in Switzerland.

The rest of the paper continues by defining our theoretical background, then presenting the research design and methodology we adopted. Then, we structure our findings around the above stated research questions. Finally, we discuss the implications of our research for theory and practice.

\section{Related Work}

\subsection{Blockchain technology}

The popularity (rather the hype) of blockchain technology emerged from the famous cryptocurrency Bitcoin. At present, cryptocurrencies have a negative connotation due to speculation, related scandals and darknet activities, and extreme power consumption. However, cryptocurrencies are only an application of blockchain, so blockchain may move beyond its main 'killer-app', cryptocurrencies, by providing an infrastructure for other services. Depending on its design and configuration, it may bring value to resolve problems, in which different, unknown, and untrusted parties may be involved [8].
In this subsection, we briefly explain the notion of blockchain technology, its key concepts and characteristics. It is important to note that the technology is still in the exploratory phase; some say it is a solution in search of problems. Even though there are plenty of on-going projects in research and industry, most of the applications are in an experimental phase, and thus it is too early to say that they will fulfil its revolutionary promises [9]. However, there are several studies that make steps toward developing understanding of the technology by conceptualizing and characterizing its capabilities.

A blockchain is a distributed ledger that is replicated and shared among nodes of a network [10]. The use of asymmetric cryptography brings authentication, integrity, and immutability to blockchains [10]. Once a transaction is certified by a node, it is broadcasted to other nodes in the network. These nodes verify the validity of incoming transactions and spread them further in the network. One of the most remarkable properties of blockchain is claimed to be trust [11], as nodes in the blockchain network do not have to rely on and trust each other because trust is achieved by putting transactions into the distributed ledger. This is a contentious theme because even if transactors do not need to trust one another personally in order to transact with them, it is undeniable that they have to put some level of trust in the system overall. So, while the micro level-which is investigated here-may appear to be trustless, it relates to a broader level of trust creation and maintenance, which may reduce information asymmetry.

Blockchain technology promises to establish a trusted environment while forming a decentralized network [7]. This is provided by six main mechanisms of blockchain, as illustrated in Figure 1: transparency, integrity of data, immutability and privacy; as well as system reliability and versatility. However, other researchers suggest that some blockchain characteristics also pose unique challenges to interpersonal trust management, in particular privacy of users [7], [12]. While blockchain technology can provide a tamperproof record of transactions, it cannot provide a guarantee that the other party will behave

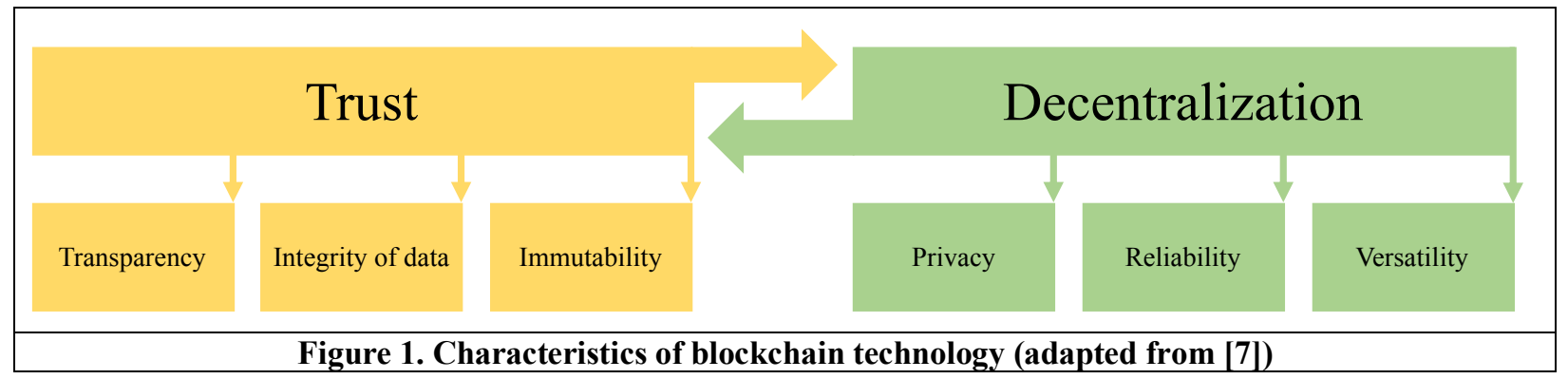


with integrity. Blockchain systems operate in a wider context of economic and social transactions that require trust between individuals. Therefore, blockchain does not eliminate the need of trust between individuals, but serves as its enabler [13]. Although blockchain technology can bring certain value for service systems due to its design and inherent properties (like immutability, transparency, integrity of data, etc.) [14], the technology itself is not a holy grail that is able to resolve any emergent issue. Moreover, from the perspective of end consumers, there are challenges of technological, organizational and human nature, that have to be first overcome before the technology may be utilized [15]. These challenges include privacy issues (blockchains never forget; information is shared among participating nodes), lack of legal framework (e.g. for liability) [15]. Furthermore, as the technology is getting more mature, it is important to differentiate between different possible configurations of blockchain systems (permissions, consensus, how and what transactions are stored). Therefore, it is mandatory to study how such a system should be designed to bring the promised value.

\subsection{Information asymmetries}

In his work [6], Akerlof showed the effects of information asymmetries on markets relying, among other factors, on the example of the used car market. Information asymmetries lead to quality uncertainties, which on an individual level of buyers, cause higher costs and lead to overall dissatisfactions [16]. To resolve information asymmetries, institutions traditionally develop measures to counteract the effects of quality uncertainty (e.g., warranties, brand names and chains of organizations). The situation, described by Akerlof, is often referred to as Adverse Selection. In markets, information asymmetries are characterized by scarcity of pre-purchase information about a product (i.e., the lack of reliable information about product quality attributes), that hinders a consumer from assessing a product's quality before they buy it [17]. A customer can then only assess the product, after they actually buy it and, thus, get postpurchase information clarity.

Stemming from the field of economics and marketing, information asymmetries and adverse selection are the focus of IS research as well. IS scholars mainly study how information systems change these problems in online markets and ecommerce relationships [18]-[22], where assessment of product quality is even more difficult due to inability to examine products physically [19]. It has been proven that information technologies influence transactions between buyers and sellers by lowering search costs [23] and by reducing buyers' uncertainties about a product [22] and its seller [21]. Literature suggests that IT-enabled solutions may help reduce product uncertainties related to the description of a product and to its actual performance [22] (e.g. reputation and rating systems, and product descriptions). For example, if the buyers of used cars can gather enough detailed information independently from car sellers to determine the quality of the car, they can defy the problems of the adverse selection [5]. The problem of product uncertainty is caused not only by the dishonest behavior of sellers, but also by the inability of honest sellers to provide an adequate and comprehensive description of their product [24]. Though the economic and IS literature mentions vehicle history reports (like CarFax) as a means of reducing product uncertainty [22], no specific guidelines are provided as to how such a history report may be designed in an IT-supported setting (i.e., searching for information about a specific car online).

Blockchain technology, by its design (due to its characteristics discussed above), can provide a solution to mitigate information asymmetries and allow for better and more efficient ways of reducing quality uncertainty, therefore developing more trustful relationships between buyers and sellers. A few studies explore how blockchain technology may reduce information asymmetries in the automotive market by creating a blockchain-based vehicle history [4], [5]. These studies mostly focus on technical implementation of such a system, and process interactions between involved participants. In our study, we focus on the consumers' perspective (i.e., the perspective of car buyers). Thus, we explore how requirements for a blockchain-based system should be formulated to fulfill the promises blockchain technology makes [12], and address the needs of buyers in 'lemon markets'.

\subsection{Information seeking in the used car market}

Uncertainty exists when a framework for completing a task is in place, but necessary information to complete this task is insufficient or missing [25]. One of the traditional ways buyers cope with uncertainties in the market is information seeking, that is aimed at gathering missing information to complete the task (i.e. to purchase a car) [26]. Information seeking has been studied from different perspectives. In IS, though definitions vary [27], researchers often refer to information seeking as an active search process triggered by a recognition of an information need [28]. Consequently, information 
seeking behavior describes the way or the strategy by which individuals act in this search [27]. Byström and Järvelin developed a model of task-based information seeking and structured information seeking in three categories: subjective task, information acquired and information sources used [29], [30]. This structure leads us in our further analysis and presentation of the results. Given the context of this research-the purchase of a used car (the task to complete)—we study the latter two in more detail to show how usedcar buyers nowadays, in the "digitalization era" [31], seek necessary information and the problems they face.

In his research a decade ago, Smith [32] compared consumer behavior in the automotive market in a traditional purchase process (without Internet) with an online purchase of a car. Amongst other things, he highlighted that use of the Internet in the research phase (or in other words, information gathering/seeking phase) increases the number of available information sources, giving more comprehensive understanding about a purchased car, and in general makes a car buyer's experience more convenient and time-saving [32]. Figure 2 illustrates the difference in available sources of information presented in the study [32]: while the traditional ones (past personal experience, publications and test drives) remain, new online sources (online publications, emarketing activities, etc.) appear. In our study, we reconsider the information seeking process, identify what problems car buyers face nowadays, and look what requirements should be then placed on the design of an information system to address the buyers' needs. Worth mentioning is also the concept of 'price anchoring', as while searching for information, car buyers often try to evaluate the range of a reasonable price to pay in relation to something else (a friend's purchase, others deals, disposable income, etc.). Price anchoring describes the effect of giving the reference price for decision-making during a purchase [33].

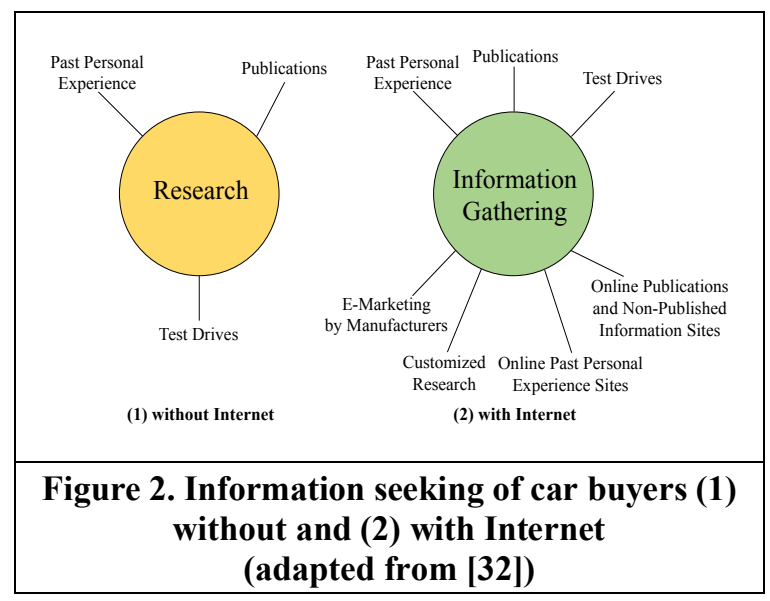

\section{Research Design and Methodology}

This study is part of a large design research project, that focuses not only on the elimination of information asymmetries in the used car market in Switzerland, but also on improving the processes across the whole carrelated ecosystem (which includes import, insurances, registration, repair works and services, etc.) with the application of blockchain technology. However, in this paper, the focus is put solely on the perspective of used car buyers and excludes organizational perspectives.

We take an approach, including qualitative and quantitative methods [34], that helps us to better understand the problems and needs of individuals, and how they relate to the emerging field of blockchain applications. Considering methodological advice not to overlook the difference between what people say they do and what they practice [35], we triangulated different data sources (semi-structured interviews and surveys) to gain a reliable interpretation of used car buyers' information behaviors.

Interviews. We studied how actual buyers cope with asymmetry of information through information seeking to cut a better deal, or avoid a bad one, in the Swiss second-hand car market. Two rounds of semistructured interviews [36] were conducted with recent car buyers (last used car bought within the last year). 10 car buyers were interviewed in each of the rounds. The first round of interviews took place between May and June 2017, and the second round of the interviews took place between March and April 2018. A questionnaire was devised relying on Byström and Järvelin's work [29], [30]. The questions were openended to allow the interviewees to present their actual experiences without being required to fit into a tight, pre-defined analytical structure. We took special care to stay as close as possible to buyers' experiences and inputs. To achieve this, possible considerations for answers were only suggested in brackets, and were used only to elicit more articulate answers in cases where the interviewee misunderstood or digressed from our questions. Though the goal of both rounds was to identify the problems the buyers experienced and to understand their needs and behaviors, in the second round a scenario and a mockup (developed during the course of the research project [37]), which illustrated a blockchain-based vehicle history application, were introduced to interviewees in order to validate the proposed requirements [38]. The interviews were then transcribed and coded [39], [40]. The codes were structured on the basis of the concepts from the information seeking model [29], quality uncertainty [22] and blockchain technology characteristics [14]. 
Online Survey. The interview responses served as the basis for the design of the survey. The survey was conducted in cooperation with one of the largest online platforms for used cars in Switzerland, in April 2018. The survey participants were users of the online platform, who were contacted via a mailing list and were asked to fill out the survey. As compensation, each survey participant had the chance to win one of five coupons worth approx. $€ 42$ each. 776 users participated in the survey, of whom 564 fully completed the survey. In this paper, we consider only the data from fully completed responses. $53 \%$ of all respondents were aged between 26 and 45, 34\% between 46 and $60,7 \%$ over 60 and $6 \%$ under 25 . $93.8 \%$ of the respondents were male. $88.6 \%$ of the respondents had already found and bought a car through an online platform at least once. By "bought through an online platform" we mean the search, choice and contact processes, as the purchase in most cases (at least in Europe) still requires a personal contact and examination of a car. All participants received questions about the problems they experienced while searching for information about a car purchase, and we were able to rate them (on a 5point Likert scale) according to their importance. Furthermore, they were asked to rate the importance of factors that influenced their choice of information sources in purchase, and criteria they paid attention to while examining certain information on a product. Finally, the respondents were asked to rate the importance of certain functionalities of a blockchainbased vehicle history, visualized on a mockup.

\section{Findings}

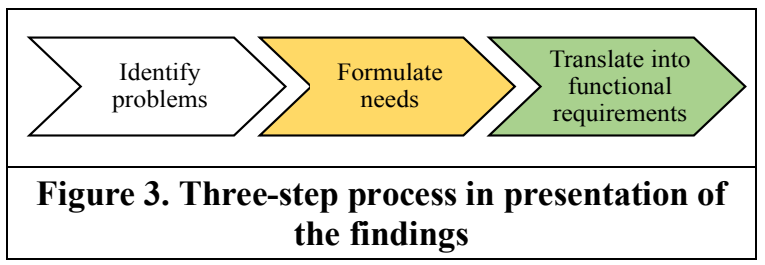

We structure our findings in line with the stated research questions. First, we explore the problems used car buyers face during the information seeking phase in a car purchase process, how their needs may be formulated, and then how these needs may be translated into functional requirements for a blockchain-based vehicle history. Figure 3 illustrates this process.

\subsection{RQ1: What problems do car buyers face in the used car market during the information seeking phase?}

The identified problems can be structured along three main themes (which follow the concepts from the theory on information seeking behavior [30]): task, information and source. In our study, we take an explorative approach with the goal of not only identifying the problems but also gaining a deeper understanding of them for the used car market case from the end consumers' perspective. The results are summarized in Table 1.

It is important to note that the study was conducted in Switzerland, where the average level of trust between individuals and between people and

\begin{tabular}{|c|c|c|c|}
\hline \multicolumn{4}{|c|}{ Table 1. Problems and derived needs of used car buyers during information seeking } \\
\hline $\begin{array}{l}\text { Information } \\
\text { seeking }\end{array}$ & & Problems & Needs \\
\hline Task-related & $\begin{array}{l}\text { Large } \\
\text { amount of } \\
\text { effort for } \\
\text { information } \\
\text { seeking }\end{array}$ & $\begin{array}{l}\text { - Evaluating the information is time- } \\
\text { consuming and effortful } \\
\text { - Involvement of third parties (e.g. friends, } \\
\text { experts) is often needed }\end{array}$ & $\begin{array}{l}\text { N1. Get assessment } \\
\text { information on the car's } \\
\text { quality, its current and future } \\
\text { expected performance and the } \\
\text { effect of these on the price } \\
\text { they pay. }\end{array}$ \\
\hline $\begin{array}{l}\text { Information- } \\
\text { related }\end{array}$ & $\begin{array}{l}\text { Uncertainty } \\
\text { of } \\
\text { information } \\
\text { quality }\end{array}$ & $\begin{array}{l}\text { - } \text { Missing information } \\
\text { - } \quad \text { Falsified information } \\
\text { - Verification of the information is difficult }\end{array}$ & $\begin{array}{l}\text { N2. Get full history of a } \\
\text { vehicle, which cannot be } \\
\text { manipulated over time, and is } \\
\text { visible to anyone interested. }\end{array}$ \\
\hline Source-related & $\begin{array}{l}\text { Uncertainty } \\
\text { of quality of } \\
\text { information } \\
\text { source }\end{array}$ & $\begin{array}{l}\text { - Choice of information sources is } \\
\text { cumbersome } \\
\text { - Trustworthiness of sources of information } \\
\text { - Ability of the source of information to } \\
\text { fulfill personal needs is questioned }\end{array}$ & $\begin{array}{l}\text { N3. Have recognizable, } \\
\text { reliable and trustworthy } \\
\text { information sources that have } \\
\text { no bias in providing wrong } \\
\text { information. }\end{array}$ \\
\hline
\end{tabular}


institutions is high in comparison to other countries [41].

Large amount of effort for information seeking.

As our results show, information seeking consumes most of a car buyer's time during the whole purchase process. $76 \%$ of survey respondents stated that they spent more than 2 weeks searching for a car and consulting various information sources. These information sources are both online and offline. Car buyers are forced to collect most of the available information themselves: on seller, on brand, on performance of the chosen model and on the specific car, that takes much time and effort in decisionmaking. To get a better understanding, second opinion or emotional support, buyers often involve third known parties in the search process. Interviewees confirmed that personal preferences play an important role in the search and selection process. However, the opinions of other trusted people may influence the decision (e.g. "if my colleague says that he would not recommend buying this car, I would have doubts all the time, even if I liked it very much"). Furthermore, personal contact and test drives are still an important or very important $(86.1 \%$ of respondents) source of information during the selection process. Generally speaking, during information seeking, buyers try to come up with a comprehensive picture of the car's quality, its current and future expected performance and the effect of these on the price they pay. Therefore, we formulate the need (N1) accordingly.

Uncertainty of information quality. As our results show, car buyers struggle with the poor quality of information provided when searching for a car. The quality of information is hindered by several factors: missing information, falsified/incorrect information, and, in general, the difficulty of verifying the provided information.

As an example of missing information, one interview partner said: "...some information on the car got lost. For example, a car with warranty was sold without the warranty just because the seller didn't know that the car still has the warranty. It was discovered first then, when the car was brought to the official vehicle service provider". Thus, information may be forgotten, and documentation may be missing. However, it may also be hidden or falsified on purpose to achieve a better price for sale: "Sometimes even photos, provided on online platforms, are photoshopped or just copied from the Internet and then uploaded on the platform". Interview partners and survey respondents claimed that the problem of falsified information (be it mileage, accident and service history, or general state) is still highly relevant and critical. Lastly, the fact that there is no way to directly verify the information provided on the platform, led to uncertainties and difficulties in the purchase process. One interview partner claimed: "You can check the photos and the information about the car only by physically seeing and trying it". Another one stated: "To verify the checkups, you need to see the original service book or a proof from an authority". Thus, one of the biggest problems is the verification of documents that prove the quality of the car and the correctness of the data. Summing up, 67\% of all survey respondents confirmed that the abovementioned factors (missing information, falsified information, and difficult verification) are problematic in the current situation. Therefore, we formulate the need (N2) for a complete history report reflecting events occurring during a car's lifetime, that cannot be manipulated and is visible to any interested party.

Uncertainty of quality of information source. Another aspect that is relevant for car buyers is the source of information about an offered specific car. As the information about the car is provided by the seller in most cases, its trustworthiness is questioned, as buyers believe that the seller always acts in the way that will maximize his profit ("...the seller is the least reliable person-he just wants money"). Thus, the information that is provided about a car is not reliable, as the source is often single and perceived to have a certain bias to manipulate the information. However, related to this, another problem occurs: not every seller is able to provide the needed information that is relevant for the buyer. It might be due to a lack of necessary expertise or a lack of willingness to invest the necessary time into tailoring the information for the needs of a certain buyer ("sometimes they (sellers) do not really bother themselves with answering questions"). Interview partners also added that they believed private sellers are less reliable than professional dealers because of the reputation dealers are afraid to spoil. Therefore, buying from a private seller, the information should be re-checked more thoroughly. $67.1 \%$ of respondents to the survey stated that they prefer a car offered by a professional dealer to one from a private seller. To sum up, in the presence of variety of information sources, car buyers still lack a reliable, trustworthy and independent source of information. Therefore, we formulate the need (N3) accordingly.

\subsection{RQ2: What requirements should be placed for the design of a blockchain-based system to address these problems?}

In this subsection we translate the identified needs of buyers into functional requirements for a blockchain-based vehicle history application. These requirements were then discussed in the second round 
of interviews with car buyers on the basis of the presented scenario and mockup. Table 2 summarizes the formulated functional requirements, derived from the needs (N1 - N3), discussed above. Here we discuss the requirements for the design of a blockchain-based vehicle history, derived from the needs car buyers have during information seeking.

Information assessment. The first requirement emerges from the need (N1) for a comprehensive assessment tool that can be used to assess the quality of the information provided. Due to the fact that the level of experience and expertise in the assessment of information quality is heterogeneous, a tool that provides assessment of information quality is seen as

\begin{tabular}{|c|l|}
\hline \multicolumn{2}{|c|}{$\begin{array}{c}\text { Table 2. Functional requirements for } \\
\text { blockchain-based vehicle history }\end{array}$} \\
\hline Needs & Requirements \\
\hline $\mathrm{N} 1 \rightarrow$ & $\begin{array}{l}\text { Information assessment: Provide analysis } \\
\text { of stored data from the past, its effect on } \\
\text { an actual value of a car and prediction on } \\
\text { its performance in the future. }\end{array}$ \\
\hline $\mathrm{N} 2 \rightarrow$ & $\begin{array}{l}\text { Timeline: Provide a timeline, showing the } \\
\text { current state of a car and the course of } \\
\text { events in its lifecycle. }\end{array}$ \\
\hline $\mathrm{N} 3 \rightarrow$ & $\begin{array}{l}\text { Independent parties: Information about } \\
\text { the vehicle history should be provided, } \\
\text { recorded and/or verified by independent } \\
\text { providers. } \\
\text { Visibility: Make information providers } \\
\text { visible and reflect their past behaviors. }\end{array}$ \\
\hline
\end{tabular}

useful. This tool may visualize the product quality, the completeness of the history, the effect of the information on the price of the car ("It would be a cool feature if the price is directly indicated depending on the information inside") and predict its future performance. $73 \%$ of survey respondents found the calculation for the effect of the information on the price important or very important. However, transparency over such analysis should be provided (e.g. one of the interviewees said: "You cannot calculate it in numbers only; a number can mean much and nothing. It should be clear how the quality is assessed").

Timeline. The second requirement emerges from the need (N2) to provide a timeline that reflects the current state of a car and the course of events in its lifecycle. $89.7 \%$ of survey respondents considered the timeline, with a chronological order of events, important or very important. Blockchain infrastructure implicitly provides transparency over transactions in the ledger as well their immutability. Thus, on an application level the timeline should be visualized and represent the state changes and events in the lifecycle of each car. The timeline should include a timestamp, the record itself (i.e. event), as well as the provider of information. Clearly, it is crucial to ensure only highquality information enters the system.

Independent parties. The third requirement emerges from the need N3. Information about the vehicle history should be provided, recorded and/or verified by independent providers. This will help to reduce information asymmetry between buyers and sellers, as one of the interviewees said: "If information is provided by independent parties, then the seller will have less power, and the buyer will get more". At the same time, the information should be available not only to interested parties, but to everyone: $85 \%$ of respondents think it is important or very important that everyone has access to the stored information to create a fair system.

Visibility. The fourth and final requirement also emerges from the need N3 and calls for making information providers visible and reflecting their past behaviors to ensure that they do not act maliciously. Only $22.2 \%$ of respondents found anonymity of information providers important or very important. Interviewees confirmed that the anonymity of car owners should be preserved, while the anonymity of organizations that provide data makes rather a negative impression: "It's more trustworthy if I see the logo of a company I know, which verified the information". Another interviewee supported the idea of reflecting the percentage of entries verified by the government, which may further influence the overall evaluation of a car.

\section{Discussion}

Though IS research on blockchain technology is still emerging, there are initial successes that show blockchain-based solutions may be feasible in cases where information asymmetries hinder the market and trust can be supported. The used car market in Switzerland is, as in many other places, a complex multi-party market defined by low trust between unknown traders. In a case such as this, general trust may be improved by the introduction of a blockchainbased vehicle history [4], [5] that does not require participants to trust one another, but supporting them with a system trusted by design [14].

The goals of this study were, firstly, to identify problems used car buyers face during information seeking (to answer RQ1); and secondly, to identify requirements that should be formulated for the design of a blockchain-based vehicle history to address and resolve these problems (thus, answering RQ2).

Our findings suggest that, despite measures taken to mitigate uncertainties [22], buyers still suffer from 
high levels of uncertainty around the quality of information available about cars they are researching during the purchase process. Although car buyers currently have access to a large number of information sources (which they may access conveniently online) [32], the more is not always the better. The choice of information sources often relies on different factors (e.g., the previous experiences and expertise of a car buyer). However, the problem buyers experience is the paradox of having a large variety of information sources available about brands, quality characteristics of certain models and their performance; while information about a specific car is not transparent and often even hidden. The credibility of information sources and the general quality of the information found is then questioned by buyers. Furthermore, even now, as digitalization penetrates almost every part of our lives [31], car buyers do not give up traditional ways of finding information about a specific car: contacting the seller and taking a test drive, as well as the involvement of third parties (with more expertise). Therefore, we can argue that the existing mechanisms (online reviews, the reputation of sellers, etc.) [22] are not powerful enough to allow a used car purchase to be completed exclusively online. Buyers tend to ask people they trust personally and who they can rely upon. However, a novel blockchain-based vehicle history can compete with these sources and become a "faceless" experienced friend while buyers are searching for a car. It is important to note, that the blockchain solution in regard to the price of a car does not reflect the "real price", which does not exist per se, but can establish a price anchor by better reflecting the quality of a car purchased.

Additionally, we can observe that most car buyers experience a need for assessment of the information about a car, and its effect on the value of the car (which might be due to lack of experience, expertise or interest in technical characteristics and performance of cars). Thus, a comprehensive mechanism should be found to express these. Blockchain technology cannot intrinsically provide this assessment, however, because of the immutability and traceability of records [14], the overall quality of the information (discussed next) and, thus, outcomes of the assessment can be improved, not least because it dissuades poor data quality entry.

Our research suggests that, currently, information seeking [42], [43] leads to quality seeking: the quality of information and the quality of information sources are what really matter to buyers. From such a broad range of information, buyers struggle to build a comprehensive understanding of the car they are attempting to buy. This situation calls for a solution that integrates the full history of a vehicle, and, at the same time, ensures its high quality (in terms of correctness, completeness of history in the system). This solution supports those honest sellers, unable to prove the quality of the car they are selling [24], while also helping to distinguish the honest sellers from the dishonest. Therefore, we may conclude that it is not the quantity of information but its quality that resolves information asymmetries. Quality seeking can now be referred to as a sub-class of information seeking.

As the design of a blockchain-based vehicle history mainly relies on data provision from different parties, it is crucial to set proper incentives for these parties to provide data of high quality. End users of the system (car buyers and car owners) cannot perceive whether the provided data is correct or not when it enters the blockchain system. While the issue of data quality (before it enters the system) remains partly outside what blockchain can affect [5], the transparency of the process and data accessibility [14], which brings value to car buyers, are potential disincentives for free-riders and lemon sellers. Thus, future research should focus on designing incentive mechanisms for the provision of high-quality data.

Furthermore, as our results suggest, the information provided about a car should be verified by independent parties. While this contradicts the need for a single source of truth, blockchain is the technology that may bring both sides together. From the one side, the creation of a single source of truth (the vehicle history), and from the other side, its decentralized character [14], which allows for verification of records by independent parties (e.g., an insurance company or a registration authority). Interestingly, though blockchain technology is always associated with its distributed and decentralized character, it is used to create centralized applications. They are centralized on an application level (e.g., one vehicle history for one car instead of various sources of information) that is based on a decentralized infrastructure. However, it requires a paradigm change in trust from buyers: trust in the application on top of blockchain technology must be developed before it may serve as an intermediary in trusting relationships between buyers and sellers, making them faceless.

Finally, the privacy promised by blockchains [14] should be studied further. From one side, due to the pseudonimity of its users, blockchain supports their privacy as identities are not disclosed [14]. However, there is no definitive version of blockchain; there are different configurations (e.g., public vs. private, onchain vs. off-chain storage of data) that should be considered for the design of blockchain-based systems [5], [8]. Our study suggests that the providers of information in a vehicle history should be visible (first, to allow differentiation between professional and 
private sellers, and also to show which records are verified by a trusted organization or institution, e.g., the traffic authority). This approach aligns with research on the influence of a brand on trust in markets [6]. However, in this case, the design of the system should handle privacy [4] and visibility differently for organizations and individuals.

\section{Limitations and Conclusions}

The properties of blockchain technology can reduce the information asymmetry between buyers and sellers. Multi-party participation, data transparency, decentralization, transaction history, and immutability all play important roles and, collectively, make blockchain technology suitable for use in the used car market. There are several challenges, such as the potential of falsification of data before it enters the blockchain and violation of privacy, which should be further studied.

We believe that the insights from this study can make a valuable contribution as they highlight the existing problems in the used car markets that are similar to processes from other markets where information asymmetries are in place (e.g., in real estate). In doing so, we contribute to information seeking literature the understanding of current problems in lemons markets as well as the concept of quality seeking, discussed above. This study also suggests the requirements for the design of a blockchain-based vehicle history, derived from the used car buyers' needs. Therewith, we extend the body of knowledge on blockchain technology in general but also inform its design implications. We see a high potential in developing studies to address other domains, where information asymmetries occur, and testing whether the formulated design requirements hold up there, too.

On the other hand, we acknowledge that further research is needed to make a stronger theoretical contribution from the micro-economic perspective. Some limitations should be admitted, which should inspire the further study. The following aspects should be taken into consideration. Information asymmetries arise in markets where potential buyers rely on some statistical data to inform their purchasing decisions. These markets are populated by both dishonest as well as honest merchants who sell cars of variable quality. Honest sellers wish to signal credibility if dishonest sellers are present. This can be done in multiple ways (reputation, credentials, excludability from social groups, warranties, online reviews etc.). For a signal to be worth something for the buyer, the signal has to be credible and affordable. Saying this, we acknowledge that now the needs and the requirements for the system should be examined under the named conditions.

Therefore, we hope to inspire further impactful research on blockchain technology, considering a large variety of aspects, from underlying cryptology, security and design, to growing blockchain-based ecosystems, their governance and business models.

\section{References}

[1] S. Lades, "Vertrauen der Deutschen in Sicherheitskräfte wächst weiter - Automobilbranche mit starken Verlusten," GfK Verein, 15-Mar-2017. [Online]. Available: http://www.gfkverein.org/presse/vertrauen-der-deutschensicherheitskraefte-waechst-weiter-automobilbranchestarken. [Accessed: 30-Apr-2018].

[2] M. R. Busse, D. G. Pope, J. C. Pope, and J. SilvaRisso, "Projection bias in the car and housing markets," National Bureau of Economic Research, 2012.

[3] European Union, "Study on the Second Hand Cars Market," European Union, Luxembourg, Oct. 2014.

[4] K. L. Brousmiche, T. Heno, C. Poulain, A. Dalmieres, and E. B. Hamida, "Digitizing, Securing and Sharing Vehicles Life-cycle Over a Consortium Blockchain: Lessons Learned," in New Technologies, Mobility and Security (NTMS), 2018 9th IFIP International Conference on, 2018, pp. 1-5.

[5] B. Notheisen, J. B. Cholewa, and A. P. Shanmugam, "Trading Real-World Assets on Blockchain," Business \& Information Systems Engineering, vol. 59, no. 6 , pp. 425-440, 2017.

[6] G. A. Akerlof, "The market for" lemons": Quality uncertainty and the market mechanism," The quarterly journal of economics, pp. 488-500, 1970.

[7] S. Seebacher and R. Schüritz, "Blockchain Technology as an Enabler of Service Systems: A Structured Literature Review," in Exploring Services Science, vol. 279, S. Za, M. Drăgoicea, and M. Cavallari, Eds. Cham: Springer International Publishing, 2017, pp. 12-23.

[8] K. Voronchenko, "Do you need a Blockchain?," 2017.

[9] D. Tapscott and A. Tapscott, "Realizing the Potential of Blockchain," World Economic Forum, Jun. 2017.

[10] K. Christidis and M. Devetsikiotis, "Blockchains and smart contracts for the internet of things," IEEE Access, vol. 4, pp. 2292-2303, 2016.

[11] R. Beck, J. Stenum Czepluch, N. Lollike, and S. Malone, "BLOCKCHAIN-THE GATEWAY TO TRUST-FREE CRYPTOGRAPHIC TRANSACTIONS," presented at the European Conference of Information Systems, 2016.

[12] M. J. Casey, "In blockchain we trust," MIT Technology Review. [Online]. Available: https://www.technologyreview.com/s/610781/inblockchain-we-trust/. [Accessed: 11-Jun-2018].

[13] M. J. Casey and P. Vigna, The Truth Machine: The Blockchain and the Future of Everything. HarperCollins, 2018. 
[14] S. Seebacher and R. Schüritz, "Blockchain technology as an enabler of service systems: A structured literature review," in International Conference on Exploring Services Science, 2017, pp. 12-23.

[15] M. Schlegel, L. Zavolokina, and G. Schwabe, "Blockchain Technologies from the Consumers' Perspective: What Is There and Why Should Who Care?," in Proceedings of the 51st Hawaii International Conference on System Sciences, 2018.

[16] G. S. Sureshchandar, C. Rajendran, and R. N. Anantharaman, "The relationship between service quality and customer satisfaction-a factor specific approach," Journal of services marketing, vol. 16, no. 4, pp. 363-379, 2002.

[17] J. D. Wells, J. S. Valacich, and T. J. Hess, "What signal are you sending? How website quality influences perceptions of product quality and purchase intentions," MIS quarterly, pp. 373-396, 2011.

[18] A. Ghose, "Internet exchanges for used goods: An empirical analysis of trade patterns and adverse selection," Mis Quarterly, pp. 263-291, 2009.

[19] J. Wolf and W. Muhanna, "Adverse Selection and Reputation Systems in Online Auctions: Evidence fom eBay Motors," ICIS 2005 Proceedings, p. 67, 2005.

[20] A. Dimoka and P. Pavlou, "Product Quality Uncertainty in Online Auction Marketplaces: Overcoming Adverse Product Selection with Price Premiums," AMCIS 2006 Proceedings, p. 43, 2006.

[21] P. A. Pavlou, H. Liang, and Y. Xue, "Understanding and mitigating uncertainty in online exchange relationships: A principal-agent perspective," MIS quarterly, pp. 105-136, 2007.

[22] A. Dimoka, Y. Hong, and P. A. Pavlou, "On product uncertainty in online markets: Theory and evidence," MIS quarterly, pp. 395-426, 2012.

[23] J. Kuruzovich, S. Viswanathan, and R. Agarwal, "Seller search and market outcomes in online auctions," Management Science, vol. 56, no. 10, pp. 1702-1717, 2010.

[24] P. A. Pavlou and A. Dimoka, "Understanding and mitigating product uncertainty in online auction marketplaces," 2008.

[25] A. R. Dennis and J. S. Valacich, "Rethinking media richness: Towards a theory of media synchronicity," in Systems Sciences, 1999. HICSS-32. Proceedings of the 32nd Annual Hawaii International Conference on, 1999, pp. 10-pp.

[26] C. Luo, C. L. Sia, Y. Shi, and H. Chen, "Managing uncertainty: An exploratory study of information seeking strategies of online consumers," ICIS 2009 Proceedings, p. 198, 2009.

[27] J.-E. Mai, Looking for information: A survey of research on information seeking, needs, and behavior. Emerald Group Publishing, 2016.

[28] D. O. Case and L. M. Given, Looking for Information: A Survey of Research on Information Seeking, Needs, and Behavior. Emerald Group Publishing, 2016.
[29] K. Byström and K. Järvelin, "Task complexity affects information seeking and use," Information processing \& management, vol. 31, no. 2, pp. 191-213, 1995.

[30] K. Byström, Task complexity, information types and information sources: examination of relationships. Tampere University Press, 1999.

[31] K. Hinkelmann, A. Gerber, D. Karagiannis, B. Thoenssen, A. Van der Merwe, and R. Woitsch, "A new paradigm for the continuous alignment of business and IT: Combining enterprise architecture modelling and enterprise ontology," Computers in Industry, vol. 79, pp. 77-86, 2016.

[32] A. D. Smith, "Exploring Dimensions of Customer Retention and Information Quality in the Online Automobile Industry.," IJEBM, vol. 4, no. 1, pp. 4863, 2006.

[33] A. Tversky and D. Kahneman, "Judgment under uncertainty: Heuristics and biases," science, vol. 185, no. 4157, pp. 1124-1131, 1974.

[34] L. Dubé and G. Paré, "Rigor in information systems positivist case research: current practices, trends, and recommendations," MIS quarterly, pp. 597-636, 2003.

[35] D. Silverman, "Qualitative research: meanings or practices?," Information systems journal, vol. 8, no. 1, pp. 3-20, 1998.

[36] M. D. Myers and M. Newman, "The qualitative interview in IS research: Examining the craft," Information and Organization, vol. 17, no. 1, pp. $2-$ 26, Jan. 2007.

[37] M. B. Rosson and J. M. Carroll, "Scenario based design," Human-computer interaction. boca raton, FL, pp. 145-162, 2009.

[38] K. Peffers, T. Tuunanen, M. A. Rothenberger, and S. Chatterjee, "A design science research methodology for information systems research," Journal of management information systems, vol. 24, no. 3, pp. 45-77, 2007.

[39] J. Saldaña, The coding manual for qualitative researchers. Los Angeles, Calif: Sage, 2009.

[40] U. Flick, The SAGE Handbook of Qualitative Data Analysis. SAGE, 2013.

[41] J. Delhey, K. Newton, and C. Welzel, "How general is trust in 'most people'? Solving the radius of trust problem," American Sociological Review, vol. 76, no. 5, pp. 786-807, 2011.

[42] K. Järvelin and T. D. Wilson, "On conceptual models for information seeking and retrieval research," Information research, vol. 9, no. 1, pp. 9-1, 2003.

[43] T. D. Wilson, "On user studies and information needs," Journal of documentation, vol. 37, no. 1, pp. 3-15, 1981. 